\title{
Organizational Learning for Library Enhancements: A Collaborative, Research-Driven Analysis of Academic Department Needs
}

\section{Jeffery L. Loo and Elizabeth A. Dupuis}

This article presents a qualitative evaluation methodology of academic departments for library organizational learning and library enhancement planning. This evaluation used campus units' academic program review reports as a data source and employed collaborative content analysis by library liaisons to extract departmental strengths, weaknesses, opportunities, threats, and priorities. We illustrate how a systematic review of internal planning documents facilitates the understanding of programmatic goals, identification of cross-unit synergies, and prioritization of library services. Our evaluation used a mix of technological, methodological, and analytical activities suitable for implementation in other academic library settings.

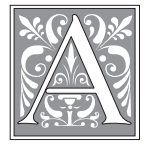

cademic environments are seeing rapid change in their intellectual, technological, and economic directions. Consequently, libraries must keep abreast of emerging issues and evolving demands, engage with their changing communities, innovate in the face of resource constraints, and communicate their actions and intentions clearly.

Such challenges drive the need for academic libraries to assess programs and plan for change in a comprehensive and strategic fashion to align with the mission of their institution. In the late 1990s and early 2000s, university libraries at the University of Pittsburgh and the University of Arizona engaged in comprehensive strategic planning to adapt to the rapid change in their academic environments. ${ }^{1}$ Near the start of this decade, many university libraries undertook major initiatives to consider their mission, priorities, services, and organizational structures. ${ }^{2}$ Cornell University Library undertook a process to re-envision their library system, stating that the Library will be "constantly re-inventing itself" as it embraces new models for facilities, organization, and collections development and access. ${ }^{3}$ Similarly, a Task Force on University Libraries was charged to study and make clear recommendations for the Harvard Library system of the 21 st century. ${ }^{4}$ After consulting with many library stakeholders,

Jeffery L. Loo is Chemical Informatics Librarian and Elizabeth A. Dupuis is Associate University Librarian for Educational Initiatives $\mathcal{E}$ User Services at University of California, Berkeley Library; e-mail: jloo@berkeley.edu, edupuis@berkeley.edu. (C) 2015 Jeffery L. Loo and Elizabeth A. Dupuis, Attribution-NonCommercial (http://creativecommons.org/licenses/by-nc/3.0/) CC BY-NC. 
analyzing library data and policies, and holding meetings and deliberations, they arrived at recommendations for a shared administrative infrastructure, rationalized and enhanced information technology systems, a revamped financial model, a rationalized collection development and access approach, and collaboration with peer institutions.

Several elements underpin each of these initiatives: data sources collected through consultation with many stakeholders, formalized assessment, and research techniques; an evaluation of the library's role and impact in academic programs; final recommendations that involve different operational levels and divisions both inside and outside the library; and the adoption of new organizational models for agility and responsiveness to future change.

In line with these efforts at other academic libraries, the UC Berkeley Library has developed an exercise to comprehensively assess academic departments for organizational learning and for identifying library service enhancements. We describe an approach that is grounded in data collected from the collaborative and qualitative content analysis of self-study reports that Berkeley academic departments prepare for their Academic Program Review (APR). An overview of the structure and workflow of our exercise is provided in figure 1 . While strategic planning activities are common, it is difficult to ground them with research methods that align well with campuswide notions of change, leadership, and assessment. Our model may serve as a first step for libraries seeking such an approach.

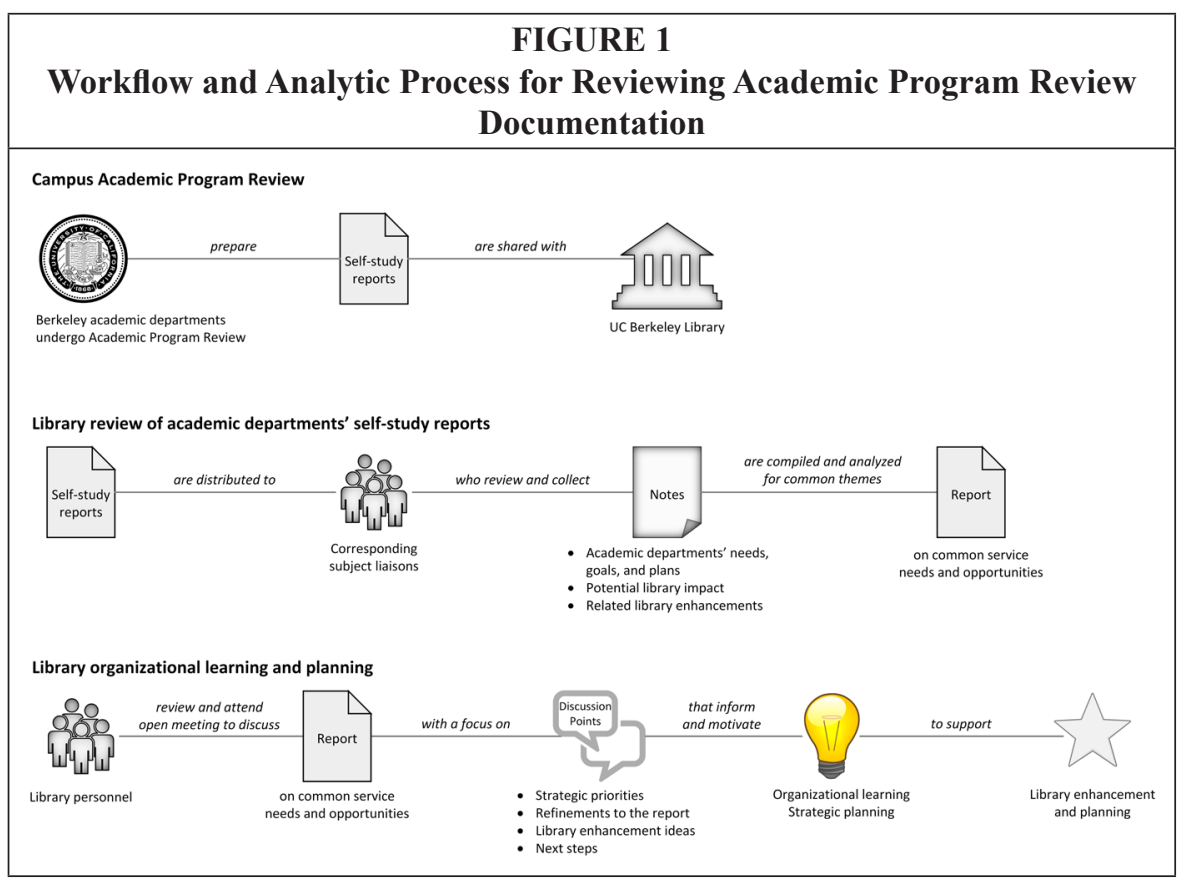

\section{Re-envisioning at the UC Berkeley Library}

For a sense of the challenges and the context that drove our pursuit of organizational learning and enhancement, we review our library's recent efforts to re-envision services toward a new and sustainable model. In September 2007, the University of California, Berkeley Library launched a New Directions Initiative to engage all library staff in exploring, understanding, and adapting to the evolving needs of our faculty and students. 
In April 2008, the Library Administration selected 26 strategic starting points related to new services, key areas of expertise, infrastructure investments, and organizational changes that we felt would strategically position the library to best meet contemporary and future demands. These starting points covered areas such as assessment, copyright, digital programs, discovery, e-research and data support, scholarly communications, and transitioning to new roles for library professionals. While many related projects launched immediately, the national economic crisis soon followed.

Like many academic libraries, the UC Berkeley Library shifted to focus on how to sustain core services in the context of budget reductions, retirements, and a hiring freeze. The Library Administration and staff recognized our need to create a new vision, better aligning library expertise and resources with faculty and students' contemporary research, teaching, and learning needs. Retaining the imperative of addressing strategic issues identified in the New Directions Initiative, but coupled with the acknowledgement of more limited funding, in December 2011, the UC Berkeley Library embarked on a process to re-envision library roles and services. ${ }^{5}$

As a first step, it was critical to develop a shared understanding within the library of our organization's current state and future goals to ensure that our resulting directions were visionary, feasible, and broadly embraced. To build this shared understanding, two self-study teams were formed: one team examined services to propose new models and configurations with staffing and cost evaluations, and a second team examined the role of the librarian to recommend approaches for service excellence as a premier academic research center with consideration of organizational structures, equitable workload, and emerging areas of expertise. Both teams gathered and analyzed data that informed a broad self-study conducted by the library. This process was guided by the Library's Statement of Purpose, Statement of Values, and Re-envisioning Principles. ${ }^{6}$

The self-studies were released for review and comment by the full range of our community - faculty, graduate students, undergraduates, library staff, and the campus academic administration. Additionally, an online survey for the campus was conducted to gain feedback on our recommendations. ${ }^{7}$ The process led to the formation of a Commission on the Future of the UC Berkeley Library to inform the library's re-envisioning and implementation planning. While this planning process yielded productive recommendations, it was difficult to point to evidence drawn from particular academic departments, programs, and campus communities. Consequently, the library embarked on a project to gather more insight. When identifying available data sources, the key challenge was obtaining departmental input without deploying another survey.

At Berkeley, the Office of the Vice Provost for Teaching, Learning, Academic Planning \& Facilities coordinates the Academic Program Review (APR) exercise as an opportunity for academic departments to take a comprehensive look at their opportunities and challenges, assess their future, and pursue new paths of inquiry and discovery. ${ }^{8}$ In the 1970s, academic institutions in the United States began employing academic program reviews for quality assurance exercises, and over time they have been adopted to demonstrate institutional effectiveness and accountability, to serve as a pathway for the continuous enhancement of program quality and currency, and to guide resource allocations and other institutional decision-making. ${ }^{9}$ There are a variety of models and structures for conducting program reviews. ${ }^{10}$ The general process includes the "self-study inquiry and report, followed by the external review, then a formal findings and recommendations report, and culminating with a memorandum of understanding that may involve commitments from senior administrators regarding resources." ${ }^{11}$ University accrediting agencies have recognized the potential of the academic program review for fostering continuous improvements for retention, curricular development, resource allocation, decision-making, strategic planning, and more. ${ }^{12}$ 
The library literature has explored academic program reviews in terms of academic libraries playing a meaningful, proactive role in the review process and contributing to campus governance..$^{13}$ However, there has been little exploration of how libraries may use the resulting self-study reports for their own strategic advancement.

Each Berkeley academic department is scheduled for a program review every eight years. The resulting APR self-study reports serve as a snapshot of academic departments and provide valuable insight into the strategic plans, experiences, and needs of academic departments. These details can help the library enhance its services, programs, and resources with a greater sense of focus and impact. The Vice Provost approved the library's request to receive copies of all past and future APR reports prepared by academic departments.

With this data source in hand, our library then designed the methodology for subject liaisons to review the APR self-study reports of the academic departments they serve. Following the individual reviews, liaisons would be equipped to hold self-led focus-group-style meetings to identify common threads across our university, distinct user needs, and potential library enhancements to inform our re-envisioning process.

\section{Literature Review}

A number of catalysts are challenging the academic status quo, and management of the resulting change is critical for libraries. In recent years, financial constraints have taken center stage. Technological innovations, particularly digital and integrated services, have been a driving force for development as well as a challenge to library budgets. ${ }^{14}$ User behavioral shifts are reshaping expectations to align with new research, learning, pedagogy, space, and service paradigms. ${ }^{15}$ Organizational accountability also drives the need to assess our contributions, outcomes, and impact to demonstrate organizational relevance. ${ }^{16}$

Organization development is an established practice for managing these types of changes. It is a systemic approach to reshaping processes, structures, and attitudes to address challenges. ${ }^{17}$ French and Bell define organization development as the effort to " $[. .$.$] improve an organization's visioning, empowerment, learning, and problem-$ solving processes, through an ongoing, collaborative management of organization culture [...]." ${ }^{18}$ The core elements include customer satisfaction, human capital development, continuous improvement, involvement and participation, common vision, entrepreneurial spirit, organizational culture, and empowerment. ${ }^{19}$

Organization development is not foreign to academic libraries. In a 2004 issue of Library Trends devoted to organization development and leadership, researchers noted a natural resonance between this paradigm and library cultures. ${ }^{20}$ Additionally, a 2010 survey of ARL institutions found that many academic libraries are using organization development practices informally and in formal programs. ${ }^{21}$ For example, 37 library deans out of the 38 institutions surveyed indicated some level of engagement with activities like strategic planning, training and development, working groups, assessment, and the learning organization.

The learning organization is an important concept to organization development. Oakleaf provides an overview of organizational learning and justifies its relevance to academic library operations. ${ }^{22}$ She cites Garvin's succinct characterization: learning organizations are "skilled at creating, acquiring, and transferring knowledge and at modifying [their] behavior to reflect new knowledge and insights" and they rely on systematic problem-solving strategies, data for decision-making, and experimentation. ${ }^{23}$ Additionally, when Peter Senge coined the concept of the learning organization, he outlined five underlying disciplines that enable it. They include personal mastery (that is, elements of vision, focus, patience, and so on), mental models (in other words, how we understand and interpret the organization), a shared vision, team learning, 
and systems thinking. ${ }^{24}$ The latter is about a shift "from seeing the individual parts of a system to understanding that the system is an interaction of these parts." 25 Taken altogether, organizational learning is about action: to broadly gather information about an organization, to create knowledge from it, and then to use this knowledge to improve the organization. ${ }^{26}$

There are many strategies to organizational learning, and they center on connecting learning with organizational operations, committing to its continuous process, developing a shared vision through team learning, and capturing and sharing the resulting knowledge for implementation and application to practice. ${ }^{27}$ These characteristics and activities of organizational learning are relevant to libraries because they foster a process with elements of awareness, focus, adaptability, and innovation that may help librarians address the rapid changes in academic and information environments. ${ }^{28}$ As Fowler succinctly notes, "learning and innovation in an academic library may fuel each other" for meeting the challenges faced. ${ }^{29}$

We saw that a number of libraries have had success with organization development for managing library change, particularly through organizational learning activities. ${ }^{30}$ Subsequently, we reviewed the literature to identify the core values and activities that underlie the effective approaches taken. This led to our compilation of best practices for guiding our library's organizational learning exercise (see table 1).

\begin{tabular}{|c|c|}
\hline \multicolumn{2}{|c|}{$\begin{array}{c}\text { TABLE } 1 \\
\text { Best Practices for Organization Development and Organizational Learning } \\
\text { in Academic Libraries }\end{array}$} \\
\hline Values and Activities & Best Practices \\
\hline Receptivity to Change & $\begin{array}{l}\text { - Commit to becoming an agile and flexible organization } \\
\text { that fosters learning, experimentation, open exploration, } \\
\text { and risk-taking } \\
\text { - Embrace a drive for improving library services and } \\
\text { resources } \\
\text { - Operate in a manner that is "embedding and } \\
\text { perpetuating change in academic libraries"33 }\end{array}$ \\
\hline $\begin{array}{l}\text { Alignment with Institutional } \\
\text { Goals and Outcomes }\end{array}$ & $\begin{array}{l}\text { - Demonstrate library support of and impact on university } \\
\text { learning and research goals and outcomes } \\
\text { - Participate in institutionwide planning exercises to set } \\
\text { new pathways and partnerships with the university }\end{array}$ \\
\hline Systems Thinking & $\begin{array}{l}\text { Engage in systems thinking and take a holistic } \\
\text { perspective to facilitate collaborative action }{ }^{36} \\
\text { - Conduct an environmental analysis that explores } \\
\text { trends and shifts in the political, economic, social, and } \\
\text { technological environment }{ }^{37}\end{array}$ \\
\hline Collaborative Efforts & $\begin{array}{l}\text { Cultivate teams as a fundamental unit for learning, } \\
\text { dialogue, awareness, and problem solving }\end{array}$ \\
\hline Assessment & $\begin{array}{l}\text { - Use evidence collected from assessment and } \\
\text { stakeholder analysis to inform complex organizational } \\
\text { decision-making and foster data-based decisions }{ }^{39} \\
\text { - Develop a culture of assessment to continuously } \\
\text { evaluate and demonstrate the value of the library's } \\
\text { contributions to wider institutional goals } \mathrm{s}^{40} \\
\text { - Examine the library from the different perspectives of } \\
\text { stakeholders }^{41}\end{array}$ \\
\hline
\end{tabular}




\begin{tabular}{|c|c|}
\hline \multicolumn{2}{|c|}{$\begin{array}{c}\text { TABLE } 1 \\
\text { Best Practices for Organization Development and Organizational Learning } \\
\text { in Academic Libraries }\end{array}$} \\
\hline Values and Activities & Best Practices \\
\hline Learning & $\begin{array}{l}\text { - Support the "ability [of the organization] to learn and } \\
\text { create innovative and timely solutions" } 42 \\
\text { - Connect organizational learning with action by } \\
\text { developing the skills, capacity, and activities to improve } \\
\text { the organization's work processes }{ }^{43}\end{array}$ \\
\hline Communication & $\begin{array}{l}\text { Capture and share the learning gained from assessment } \\
\text { and planning in order to demonstrate commitment and } \\
\text { to motivate library personnel }{ }^{44}\end{array}$ \\
\hline $\begin{array}{l}\text { Continuous and Cyclical } \\
\text { Activities }\end{array}$ & $\begin{array}{l}\text { - Embed strategic planning into regular library operations } \\
\text { and employ training, assessment, problem-solving, and } \\
\text { planning when changes arise }{ }^{45}\end{array}$ \\
\hline
\end{tabular}

These best practices resonated with the needs of our organization. The UC Berkeley Library is a large academic library system serving a research-intensive university community of approximately 25,500 undergraduate students, 10,000 graduate students, and 1,500 faculty across 130 academic departments and more than 80 interdisciplinary research units. The library serves this diverse population across 20 geographically diverse campus library locations with a collection of more than 11 million volumes. Providing responsive and customized services to such large and diverse groups across a distributed library system is challenging. It is difficult to see big picture campus needs and to collaborate on initiatives and programs across the different subject-specific libraries. A broader organizational perspective might help our liaison librarians collaborate on more unified and comprehensive programming that addresses wider campus needs. Therefore, the holistic perspective of systems thinking as well as the need for collaborative efforts were best practices that resonated with our library. They may help individual liaison librarians to share best practices and to receive peer support for tackling difficult library needs. Because of the intensive research environment of our university, we also saw the importance of understanding emergent institutional goals and outcomes. This ensures that we allot our limited resources for greatest impact and align with campus advancement goals in a flexible and responsive manner. With the rapid pace of change in academic environments, we also saw the value of continuous and cyclical assessment to check in periodically with how we are meeting academic needs and to refresh our awareness of new research directions. Together, these best practices justified the relevance of organizational learning to our library's re-envisioning and strategic planning.

\section{Methodology}

\section{Research-driven Design}

Our study employed a research-driven approach to gather evidence that will deepen our understanding of academic departments, inform future decision-making about library service, and facilitate replicable and longitudinal analysis. These goals require in-depth data on the behavior of academic departments that may be complex and hard to quantify, requiring internal knowledge of the departments for context.

For this type of multifaceted data collection, qualitative research methods are well suited. Whereas quantitative social research "[counts] incidents related to human behavior," qualitative research is a suite of activities that describes little-known 
phenomena, captures meaning (such as thoughts, feelings, or behaviors) rather than numbers, and describes "processes rather than outcomes." 46 Qualitative research advocates a "human-centered approach" that resonates with the customer service ethic of libraries. ${ }^{47}$ Qualitative findings can also complement the quantitative surveys of our community by collecting unique cases and stories about user experiences. The suitability of qualitative research in library and information science is also evident from a review by Given. ${ }^{48}$

Specifically, our study employed qualitative content analysis. This is "a research technique for making replicable and valid inferences from texts (or other meaningful matter) to the contexts of their use." ${ }^{49}$ In our case, we reviewed departmental APR selfstudy reports to identify academic departments' needs and experiences with library services. By Robson's evaluation, a content analysis is advantageous by permitting an intensive understanding of subjects without obtrusive observation, time-intensive discussion, or extended fieldwork for ethnographies..$^{50}$ To conduct a qualitative content analysis, White and Marsh provide a comprehensive overview of the methodology. ${ }^{51}$ There are four general procedures that may run serially, concurrently, or cyclically and may evolve with the knowledge developed during the course of study. ${ }^{52}$ First, determine the research questions for the problem and then select relevant texts for data. Afterward, identify representative or critical units of the text (such as key quotes or examples) that correspond to the research questions. Next, code the identified units of text (that is to say, apply labels/tags that identify the concept, pattern, theme, or meaning that underlies or is reflected in the text). Coding permits the categorization of quotes and examples for comparison and analysis of themes. Finally, engage in memoing, which is the reflective review of themes, meanings, concepts, contexts, and examples to formulate conclusions, answers, and ideas.

Our research objective was to identify library enhancements that align with academic departments' needs, experiences, and advancement goals. We had three research questions:

1. What are the key changes, priorities, activities, goals, and developments within Berkeley academic departments?

2. How would these issues impact our libraries?

3. What enhancements would align the library with academic departmental advancement and activities?

In exploring these questions, we focused on four principles for organizational learning identified in our literature review. First is an open and qualitative exploration to identify new, emerging, or overlooked ideas and issues. Second, we fostered an inclusive and participatory process that relied on internal peer support to determine diverse academic needs, identify transdisciplinary trends, and share learning. Third, a methodical approach - with standard evaluative frameworks and instructional manuals and training sessions on the research methodology for library liaisons-ensured a consistent and replicable analysis. Finally, with evidence-based procedures, we grounded our library enhancement designs in organizational learning findings that have been validated and prioritized by our library personnel.

For our data source, copies of the APR reports were acquired from the Office of the Vice Provost of Teaching, Learning, Academic Planning \& Facilities at the University of California, Berkeley. The process of securing and securely distributing these reports to liaisons was made easier by showing exactly how these reports will be analyzed and discussed and what outcomes will be made public. In exchange for unprecedented access to these files, the library ensured that these reports would remain confidential and be used solely for informing the library's ability to better serve our faculty, students, and staff. The library developed a secure digital repository where PDF copies of the 
reports are uploaded, stored, and distributed via password-protected login. Because of organizational assurances and technical security, library liaisons were granted access only to reports for the departments with which they had primary subject liaison responsibilities, and they affirmed their understanding of the confidentiality along with their login to the site. These processes were modeled on techniques recommended in the Institutional Review Board literature.

\section{Analytical Frameworks}

We developed three frameworks to structure the APR report analysis process to help liaisons understand these reports, read them quickly, analyze the issues, and then collect data and ideas for library enhancements. These frameworks were beneficial in reducing the barriers to participation for the exercise and created a common language for our library system to discuss our learning on academic departments' needs.

Because the reports can be hundreds of pages long, our first framework, APR Themes Relevant to Libraries (see figure 2), helps library liaisons focus their analyses on those themes and issues in APR reports that are most relevant to library resources, services, and operations. Developed from a content analysis of the guidelines for APR self-study preparation, the framework illustrates how an academic unit consists of people in academic relationships together in a space; the academic unit moves along a path toward quality scholarly activities and makes advancements along the way; the academic unit receives support in this endeavor. Not all details in the APR reports relate to libraries. For instance, it can be difficult to determine the library's influence on a department's financial resources or its internal human resources and recruitment procedures.

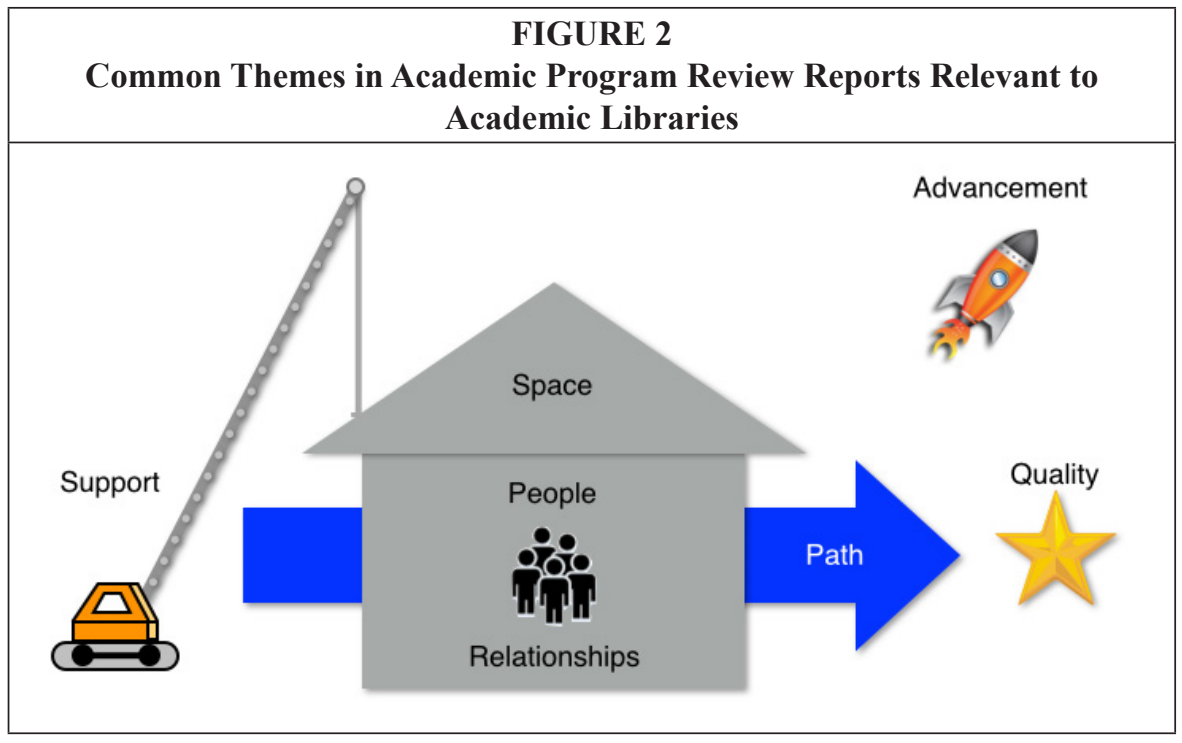

The framework of themes directs library liaisons to the APR report content for understanding the scholarly enterprise of an academic department. The people theme spans issues like diversity, demographics, and recruitment goals - all of which enable the library to identify target audiences and underserved populations. Relationships cover the partnerships, collaborations, mentorships, interactions, and scholarly discourse of 
the academic department. Exploration of these issues may help libraries understand how partnerships with the department may be forged. Space has physical and online dimensions, and their details can inform how libraries may embed into classrooms, laboratories, and online learning management systems. The path covers the academic goals, activities, and barriers that form the scholarly enterprise, and together they help the library understand what departmental ventures to support. Quality can be defined as positive experiences, achievements, strengths, measures of success, and attainment, which shed light on a department's competitive advantage. Details on advancement include the new directions and innovations of the department, which reveals to libraries the emerging issues for pursuit and alignment. A department's support includes funding resources and administrative operations - knowledge of which may uncover the decision-making culture of the department.

After identifying relevant issues from the APR reports, our second framework helps liaisons make sense of them by categorizing them along the dimensions of helpful versus harmful elements and internal versus external contexts. These dimensions suggest responsive actions that libraries could take. Helpful elements to academic departments should be supported and enhanced, while harmful elements need mitigation. The internal versus external contexts point to the direction of library support, either working within internal department environments or addressing wider and external academic trends. The intersection of these categories can be succinctly expressed as strengths, weaknesses, opportunities, threats, and priorities (SWOT+P). Table 2 summarizes this SWOT+P framework, which is an extension of the established SWOT analysis for strategic planning. ${ }^{53}$

\begin{tabular}{|l|l|l|}
\hline \multicolumn{3}{|c|}{ TABLE 2 } \\
SWOT+P Elements and Their Role in Library Planning (Definitions Based \\
on Brennan)
\end{tabular}

Our third framework, the Library Enhancement Design Process, helps library liaisons document their learning from the SWOT $+\mathrm{P}$ analysis and then move toward proposals for tangible actions and applications to practice. In this guided process, we asked liaisons to record notes on their learning of departmental issues and then to document their reflections on the impact these issues may have on 
the library. In light of this impact, liaisons then brainstorm and propose library enhancements in the domain where libraries may participate or contribute. In an example of this design process, a library liaison identified a growing partnership and alignment between two separate disciplinary groups on campus. She noted the potential impact of increased demand from these departments for collection resources and library instruction in this interdisciplinary space. Consequently, the liaison proposed as a library enhancement an increased collaboration with the relevant subject-specific liaisons for interdisciplinary collection development and instructional programming. A worksheet guided library liaisons through this process of learning documentation, determination of the connection to the library, and brainstorming for solutions or enhancements. This worksheet was distributed as a word processing document with three columns that correspond to the issue, impact, and enhancement proposal elements of the design process. Recording in this tabular format helped with compiling notes for analysis across our different subject liaisons.

To review our three analytical frameworks, the APR Themes Relevant to Libraries helps liaisons filter through lengthy APR reports for relevant issues to library operations and resources. Afterwards, the SWOT $+\mathrm{P}$ framework helps liaisons categorize the identified issues as strengths, weaknesses, opportunities, threats, or priorities to suggest how library liaisons could act upon their learning: support a department's strengths, provide support that mitigates weaknesses, align with departments' pursuit of new opportunities, recognize threats to avoid, and focus on a department's priorities. Finally, the Library Enhancement Design Process framework translates this learning into action by encouraging reflection upon the library impact of an issue to brainstorm proposals for library enhancements. Together, these three frameworks made it easier to conduct the collaborative research process among liaisons across our diverse libraries. They guided liaisons through the completion of the exercise, provided explicit instructions for the replicability of the exercise, and encouraged consistent language and standard data collection practices for a reliable analysis.

\section{Collective Data Analysis, Learning, and Planning}

To prepare library liaisons for the collective analysis of APR reports, we offered several pathways to support their participation. We developed a guidebook for self-instruction on our review exercise, with all procedures and evaluative frameworks explicitly outlined. Additionally, we conducted in-person training classes where we explained the motivation and procedures for the exercise and walked through a hypothetical example of an APR report review. Also, there was peer support, where liaisons were encouraged to discuss their findings and experiences internally with fellow liaisons in related subject areas.

After the training, our library liaisons reviewed the APR self-study reports of 18 academic departments over a two-month period. Their notes were pooled together into a spreadsheet with individual columns for departmental issues, their potential library impact, and library enhancement ideas. Each row in the spreadsheet represented a single departmental issue or a closely related set. The collected data included 236 sets of issues with their associated notes on library impact and proposals for library enhancements.

To analyze this collective data set, first we qualitatively coded the notes for common themes and findings that threaded across various academic departments. To facilitate reliability in our analysis, we had a single research analyst conduct the coding. He reviewed all of the notes for themes that appeared frequently, and this led to a set of emergent themes for us to code the findings (see table 3). 


\begin{tabular}{|l|l|}
\hline \multicolumn{2}{|c|}{ Themes from the Qualitative Content Analysis of APR Reports } \\
\hline Emergent Themes & $\begin{array}{l}\text { Pre-Defined Themes on Librarian Roles } \\
\text { and Library Functions and Services }\end{array}$ \\
\hline Change in academic departments & Access to collections \\
\hline Collections strategy & Acquisitions \\
\hline Instructional needs & Administration \\
\hline Interdisciplinary activities & Archiving \\
\hline Learning needs & Cataloging \\
\hline Patron groups & Circulation and stack management services \\
\hline Physical library space & Instruction \\
\hline Research needs & Liaison/Outreach \\
\hline Scholarly communications needs & Management (unit/department) \\
\hline Technologies and computing & Professional responsibilities \\
\hline Value of academic libraries & Reference \\
\hline & Selection \\
\hline & Web services \\
\hline
\end{tabular}

Reviewing the emergent themes, we saw that library liaisons are attuned to the change within our academic departments - particularly with interdisciplinary activities - and see specific needs arising in instruction, learning, research, and scholarly communications. In approaching these needs, the library could develop its resources along dimensions of collections strategy, physical library space, technology, and computing resources, while tailoring services to growing patron groups. And throughout these enhancements, we have the opportunity to demonstrate and promote the library's value to the university. Openly reviewing the data for common themes and frequent findings helped us see what our collective library organization is facing. It offered a general and unified perspective in contrast to the usual subject- or function-specific viewpoints.

After the review for emergent themes, we conducted a coding analysis for predefined themes on librarian roles and library services and functions (see table 3). These themes were identified previously during the Library's Re-envisioning Initiative selfstudy and capture the core actions and activities that define our library. Coding along these elements helped us connect academic departments' changes, experiences, and needs with library operations.

Rather than employ specialized qualitative analysis software, the coding process used Microsoft Excel. The decision to use Excel was made to facilitate later data analysis by our library liaisons, who widely have access to this software. Coding was accomplished by creating columns in the Excel spreadsheet with a corresponding column for each theme. If a row of notes (that is, an issue, its impact, an associated library enhancement idea) expressed a particular theme or concept, we marked an X in the corresponding column cell for that code. In this fashion, we could query the spreadsheet of notes by filtering for a code or a Boolean combination of codes.

While our analyses were qualitative, there were a few opportunities for quantitative evaluation. For instance, we calculated the frequency of the themes identified from liaisons' review notes (see figure 3). Ranking the themes allowed us to detect those issues of greatest shared interest across the academic departments reviewed. This revealed the priorities for library enhancements as perceived by our library liaisons. 


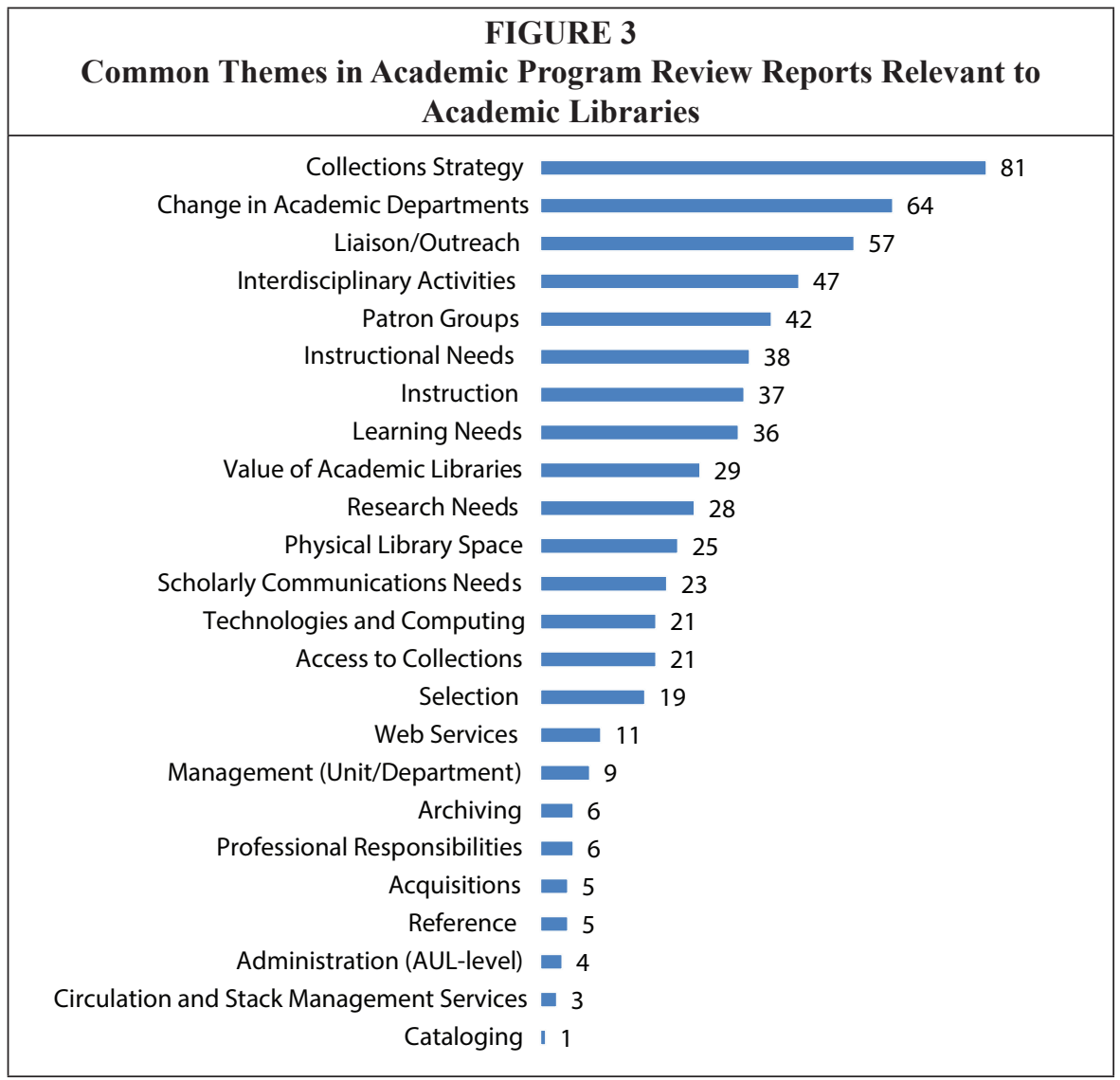

In another quantitative analysis, we counted the co-occurrence of themes (see figure 4). If one theme typically co-occurred with another theme in our liaisons' findings, this might reveal relationships among the priorities. The co-occurrences point to the intersections of issues as well as potential collaborations between working groups. For instance, we observed a high level of co-occurrence between the two themes of Collections Strategy and Change in Academic Departments and between the themes of Collections Strategy and Interdisciplinary Activities. Upon closer review, this indicated a need for collections development that addressed the increasingly interdisciplinary activities that academic departments are engaging in. Additionally, we learned that change in academic departments is primarily understood by liaisons in terms of interdisciplinary activities, patron groupings, and evolving strategies for collection development, where there are the most thematic co-occurrences. These quantitative analyses reveal patterns in the themes and offer a sense of their priority.

We prepared a final report to highlight librarywide patterns and relationships and to identify collaborative opportunities across liaison subject areas. For each theme, our report outlined the issues identified, their potential library impact, and the proposed ideas for enhancing library services. The academic departments associated with each theme were also listed. This report provided a quick overview of the issues that departments are facing; showed the connections between issues, impact, and proposed library action; and highlighted the libraries and subject specialty liaisons who are sharing similar experiences. 


\begin{tabular}{|c|c|c|c|c|c|c|c|c|c|c|c|}
\hline Frequency of Co-Occurrence & $\begin{array}{l}\text { IGI } \\
\text { Fin }\end{array}$ & $\begin{array}{l}\text { JRE } \\
\text { en E } \\
\text { ling }\end{array}$ & mer & gen & Th & ems & $\mathrm{s}$ in & Lia & son & ${ }^{\prime} \mathbf{A}$ & \\
\hline & 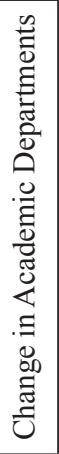 & 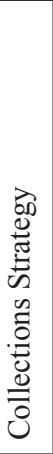 & 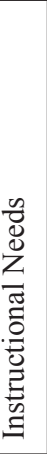 & 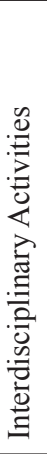 & 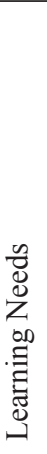 & 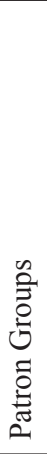 & 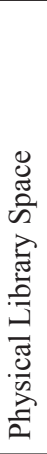 & $\begin{array}{l}\text { Dे } \\
0 \\
z \\
\overline{0} \\
\overline{0} \\
0 \\
0 \\
0\end{array}$ & 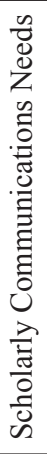 & 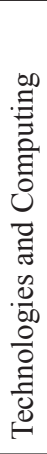 & 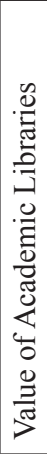 \\
\hline Change in Academic Departments & & & & & & & & & & & \\
\hline Collections Strategy & 29 & & & & & & & & & & \\
\hline Instructional Needs & 7 & 10 & & & & & & & & & \\
\hline Interdisciplinary Activities & 15 & 36 & 4 & & & & & & & & \\
\hline Learning Needs & 3 & 6 & 12 & 4 & & & & & & & \\
\hline Patron Groups & 11 & 7 & 5 & 5 & 6 & & & & & & \\
\hline Physical Library Space & 5 & 3 & 4 & 2 & 3 & 3 & & & & & \\
\hline Research Needs & 6 & 3 & 5 & 1 & 10 & 7 & 1 & & & & \\
\hline Scholarly Communications Needs & 5 & 4 & 0 & 2 & 6 & 3 & 2 & 5 & & & \\
\hline Technologies and Computing & 4 & 5 & 5 & 1 & 2 & 2 & 5 & 2 & 0 & & \\
\hline Value of Academic Libraries & 5 & 7 & 5 & 3 & 4 & 2 & 3 & 4 & 4 & 1 & \\
\hline
\end{tabular}

Internal data sharing was another element of our reporting. To help library liaisons develop a granular view of the issues and ideas proposed by their colleagues, we shared the original spreadsheet of collected notes. This enables individual librarians to query our collective notes for questions specific to academic departments or library locations. These notes were shared via our reports repository system, with password-protected access under our internal terms of use.

With the evaluation frameworks, coding models, data sharing agreements, and communication methods in place, the UC Berkeley Library is now positioned to use our APR reports review exercise for continuous assessment and strategic planning. We have a "turnkey" approach to replicating this exercise at different levels-both as a collective exercise and as an individual self-directed activity. Our three frameworks provide standardized constructs and variables for libraries to use in evaluating departmental review documents. Furthermore, these frameworks might also be used in other areas including impact assessment, marketing, and professional development by mapping library resources and services to the advancement activities of academic departments. While the method described in this paper is based on Academic Program Review reports that may not always be available, other documentation could be used as a data source including annual reports, organizational profiles, as well as departmental websites. Any artifact that documents the goals, programming, and priorities of a department could be a valuable source. 


\section{Exchange, Feedback, and Action}

After distributing the final report, we held an open meeting for all library personnel to discuss the issues and ideas from our APR exercise. This 90-minute meeting had a range of high-level outcomes that contributed to organizational learning and to the open discussion of strategic actions and collective priorities for the library's future. An opportunity for wide participation and discussion of hard and soft issues is a unique experience.

An important factor to the open meeting's success is framing the discussion to topics that all library personnel had a stake in or some experience. The first discussion topic was a reflection upon the APR review exercise. By discussing the value of the APR reports and the value of our review exercise, we engaged in a collective performance evaluation, which also cultivated a sense of camaraderie and accomplishment. Next, we prioritized and refined the library enhancement ideas from three selected themes in our final report: change in academic departments, interdisciplinary activities, and value of academic libraries. These discussions were held in small teams of approximately five members each and helped confirm our findings for validity. Finally, we discussed the future of the APR exercise by asking how the library could support academic departments to prepare and carry out APR plans.

In their feedback on the value of the APR reports, many librarians noted their impact on facilitating liaison work, particularly by informing directions for collection development and outreach activities. They found that the narrative sections of APR reports give a valuable summary of a department, which is especially helpful for liaisons beginning to work with a new academic department. Liaisons also reported developing a stronger understanding of a department's tone, climate, and folklore; what the departments value; where the departments sit politically in the campus; and what they define as their priorities and directions. Additionally, the statistics given in the APR reports help quantify a department's priorities and provide greater certainty and confirmation to liaisons' anecdotal understanding of departments.

Feedback on the value of the collective review exercise centered on the rare opportunity it presented to collectively vocalize challenges and to begin discussions on potential resolutions. Library personnel appreciated a forum to communicate new ideas and synergies across the normal subject, function, and administrative divisions of our library. They acknowledged how the discussion on a wide range of issues and ideas that altogether were practical, philosophical, and strategic shed light on the diversity of perspectives and interests within our organization.

In the discussion of next steps for our organizational learning, there were three calls for action. First, library liaisons were enthusiastic for future collective review exercises. They found the group effort to be a motivating force for peer learning and the exchange of ideas. Specifically, there was interest for library administrative direction to sustain this momentum by repeating the exercise. In response, a scheduled review cycle will regularly study academic departments' needs. This ensures that we will examine new departmental self-study reports as they are shared with the library.

Next, there was an action call for an administrative structure that will facilitate the implementation of the proposed library enhancements. Consequently, library administration has incorporated the learning from this exercise into our library's re-envisioning initiative. And to support the implementation of proposed library enhancements, three pathways were developed. At the individual level, library personnel are encouraged to pursue enhancement ideas they feel are important and then share their success with peers. For issues and enhancements that require a supportive network, liaisons could work collaboratively within their library subject or function councils on ideas that might be easier to pursue as a group. Finally, library personnel are encouraged 
to begin a dialogue that vets those library enhancement ideas that need librarywide support and then direct them to the attention of library administration-particularly for issues such as organizational structures, professional development needs, and funding requirements.

In the final call for action, library liaisons sought access to more Academic Program Review details, particularly the outcome letters that academic departments receive at the end of their review. These letters are particularly valuable since they offer a sense of where central campus administration is hoping to direct the priorities of the academic departments. Library administration subsequently contacted the Vice Provost's office and was able to secure agreement to receive copies of the outcome letters, which we now share with liaisons via our online repository together with the APR reports and our collective review data.

\section{Discussion}

The collaborative and research-driven analysis of departments' program review materials by library liaisons was beneficial to our organization in several ways. The reports added a new dimension to our understanding of academic departments' needs and experiences, and helped the library collect ideas for improving, adding, or evolving services and resources in ways that connect directly with departmental goals. Having a grounded plan that is based on best-practice recommendations in libraries and seeded with academic departments' documented needs provides the library with a strong foundation to demonstrate good faith when proposing service changes and to advocate for new services and resources.

Through this organizational learning exercise, a unique opportunity was granted to examine information services from academic departments' perspectives and to engage in deep learning and strategic planning about library services and programs. We developed new perspectives on library services "from the outside looking in," and our analysis revealed themes that we did not expect to see. For example, it was clear that the methods of resource access (such as print, electronic, interlibrary loan, and cross-institutional patron privileges) needed to be studied in light of departmental efforts in online learning. And by seeing how the library and its role were discussed in the APR reports, we also developed a deeper awareness of how the library relates to the university and individual departments, spotlighting opportunities for alignment with wider organizational initiatives. These perspectives are key to raising the library's visibility and cultivating campus awareness of the library's value.

It is important to note that we do not extensively detail specific findings from our study or our resulting strategic plans. This is primarily because our findings are based on academic departments' candid observations and self-studies, which are restricted to internal discussion. More important, our findings and conclusions might not be generalizable across external institutions since our understanding of academic departments is Berkeley specific, framed by the contexts of our institution. For instance, we identified a need by academic departments for more language learning materials, more instructional spaces and meeting rooms, and greater technology support. Findings and recommendations like these may not be relevant to other institutions facing different constraints.

Overall, our collaborative and research-driven approach to reviewing APR reports suggests an effective option for libraries engaging in strategic planning because of three defining elements. First, the collaborative content analysis approach is a novel research model with a unique compatibility to library liaisons. It leverages the unique relationship of library liaisons to their academic departments. In serving as research analysts, our liaisons are uniquely qualified because they are grounded by their professional 
objective to resolve information needs and they possess the subject expertise, research expertise, and institutional familiarity to interpret and identify information needs. These abilities enable liaisons to articulate unspoken departmental needs and interpret them in our library services context. Subsequently, liaisons may design solutions from this learning and then deliver them as practitioners. This researcher-practitioner position is unique and enables research findings to be put into practice. Having library liaisons conduct the analysis ensures that those with the greatest ability to effect change in departmental relationships will have the knowledge to act.

Second, a content analysis approach lowers the organizational cost of research for an efficient and intensive understanding of academic departments. It also provides a unique lens into departments that may not be possible through direct contact methods and surveys. For instance, analyzing candid and aspirational review documents could afford the library a behind-the-scenes look into a department's strategic advancement. This insider's perspective might otherwise take years to build from meetings and collaborations with department members. Additionally, short surveys and focus groups may not offer the reflective setting to capture the deep insights or long-term aspirational goals documented in a department's academic review. There are nuanced, rich constructs and community-articulated visions that may be very difficult to measure through individual interactions. However, as a caveat, the APR self-study reports are written for review purposes and not research purposes, so biases as well as incomplete information may inhibit the objective understanding of academic units.

Finally, our approach to APR reports review is a pathway for continuous assessment and strategic planning in the library. The replicability of this evaluation methodology with its research questions, conceptual and evaluative frameworks, documented procedures, and guided activities means we can repeat the exercise as new APR reports are generated. It provides subject liaisons with a recurring data source to complement their departmental outreach efforts. Regular assessment may also serve as a barometer of trends to shape long-term library programming and strategic directions. This exercise uniquely provides the organizational learning opportunities for liaisons to share and find mutual support for academic challenges.

\section{Conclusion}

This paper documents an approach to gathering ideas and fostering discussion among library liaisons to inform organizational learning and strategic planning. Using frameworks that helped liaisons to analyze academic departments' self-studies, library personnel collectively became more familiar with academic needs, expectations, and priorities. With this knowledge, our libraries can plan enhancements that are of intrinsic value to the institution and are responsive to changes in academia. Although there are limitations to sharing our data and findings due to the internal nature of the APR reports, academic libraries may draw upon our work to conduct a similar analysis customized to their environment. Our methodology, exercises, and frameworks espoused a systematic and research-based approach that is replicable for longitudinal assessment and encourages evidence-based decision-making for organization development. While not all institutions have access to in-depth reports and evaluations of academic departments, this exercise could be conducted with other artifacts and documents developed by academic departments and campus units. The important focus is to identify library enhancements that respond to academic changes in a manner that is open, inclusive, collaborative, and research-driven. 


\section{Notes}

1. Elizabeth J. Wood, Rush Miller, and Amy Knapp, Beyond Survival: Managing Academic Libraries in Transition (Westport, Conn.: Libraries Unlimited, 2007).

2. Matthew Conner, The New University Library: Four Case Studies (Chicago: ALA Editions, 2014).

3. Cornell University Library, "Library Strategic Planning Report Summary" (2009), available online at http://staffweb.library.cornell.edu/strategic [accessed 27 May 2015].

4. Harvard University, Report of the Task Force on University Libraries (Cambridge, Mass: Harvard University, 2009), available online at http://hwpi.harvard.edu/files/provost/files/library_task_force_report.pdf [accessed 27 May 2015].

5. UC Berkeley Library, "Re-Envisioning Library Services - Introduction" (2012), available online at www.lib.berkeley.edu/AboutLibrary/re_envision_intro.html [accessed 27 May 2015].

6. UC Berkeley Library, "Principles for Re-Envisioning Library Services" (2012), available online at www.lib.berkeley.edu/AboutLibrary/re_envision_principles.html [accessed 27 May 2015]; UC Berkeley Library, "Statement of Purpose, UC Berkeley Library" (2004), available online at www.lib.berkeley.edu/AboutLibrary/purpose.html [accessed 27 May 2015]; UC Berkeley Library, "Statement of Values, UC Berkeley Library" (2004), available online at www.lib.berkeley.edu/ AboutLibrary/values.html [accessed 27 May 2015].

7. UC Berkeley Library, Attitudes Toward Re-Envisioning The UC Berkeley Library: An Online Survey Of The UC Campus Community Conducted By Hart Research Associates (Berkeley, Calif., 2012), available online at www.lib.berkeley.edu/AboutLibrary/Hart_Survey_Report_Re-Envisioning_ UC_Berkeley_Library.pdf [accessed 27 May 2015].

8. UC Berkeley Office of the VP-TLAP\&F, UC Berkeley Guide for the Review of Existing Instructional Programs (Berkeley, Calif., 2011), available online at http://vpapf.chance.berkeley.edu/apr/ GUIDE_May2011.pdf [accessed 3 June 2014].

9. WASC, “WASC Resource Guide for 'Good Practices' in Academic Program Review," 2009, available online at www.wascsenior.org/files/Program_Review_Resource_Guide__Sept_2009. pdf [accessed 27 May 2015]; Gita Wijesinghe Pitter, "Program Review: A Tool for Continuous Improvement of Academic Programs," Association for Institutional Research: Professional File 105 (2007): 1-12; Robert J. Barak and Lisa A. Mets, Using Academic Program Review (San Francisco: Jossey-Bass, 1995).

10. Pitter, "Program Review: A Tool for Continuous Improvement of Academic Programs."

11. WASC, "WASC Resource Guide for 'Good Practices' in Academic Program Review," 6; Pitter, "Program Review: A Tool for Continuous Improvement of Academic Programs."

12. WASC, "WASC Resource Guide for 'Good Practices' in Academic Program Review"; Lisa A. Mets, "Program Review in Academic Departments," in Using Academic Program Review (San Francisco: Jossey-Bass, 1995), 19-36.

13. John Costella et al., "Undergraduate Program Review Processes: A Case Study in Opportunity for Academic Libraries," Journal of Academic Librarianship 39, no. 2 (Mar. 2013): 169-74, doi:10.1016/j.acalib.2012.09.016; Charles A. Schwartz, "The University Library and the Problem of Knowledge," College and Research Libraries 68 (2007): 238-44, available online at http://crl.acrl. org/content/68/3/238.abstract [accessed 27 May 2015].

14. Glenn S. McGuigan, "Addressing Change in Academic Libraries: A Review of Classical Organizational Theory and Implications for Academic Libraries," Library Philosophy and Practice (e-Journal), no. 755 (2012), available online at http://digitalcommons.unl.edu/libphilprac/755/ [accessed 27 May 2015].

15. Ross Housewright, Roger C. Schonfeld, and Kate Wulfson, Ithaka S+R US Faculty Survey 2012 (New York, 2013), available online at www.sr.ithaka.org/research-publications/us-facultysurvey-2012 [accessed 27 May 2015]; Lucinda Covert-Vail and Scott Collard, New Roles for New Times: Research Library Services for Graduate Students (Washington, D.C., Association of Research Libraries, 2012), available online at www.arl.org/storage/documents/publications/nrnt-grad-roles20dec12.pdf [accessed 27 May 2015]; Eden Dahlstrom, ECAR Study of Undergraduate Students and Information Technology, 2012 (Louisville, Colo., 2012), available online at http://net.educause. edu/ir/library/pdf/ERS1208/ERS1208.pdf [accessed 27 May 2015]; Wood, Miller, and Knapp, Beyond Survival: Managing Academic Libraries in Transition; Sarah McNicol, "The Challenges of Strategic Planning in Academic Libraries," New Library World 106, no. 11/12 (2005): 496-509, doi:10.1108/03074800510634982; Karen Holloway, "The Significance of Organizational Development in Academic Research Libraries," Library Trends 53, no. 1 (2004): 5-16.

16. Association of College and Research Libraries, Value of Academic Libraries: A Comprehensive Research Review and Report (Chicago, 2010), available online at http://www.ala.org/acrl/files/content/issues/value/val_report.pdf; McNicol, "The Challenges of Strategic Planning in Academic Libraries" [accessed 27 May 2015]. 
17. Denise Stephens and Keith Russell, “Organizational Development, Leadership, Change, and the Future of Libraries," Library Trends 53, no. 1 (2004): 238-57.

18. Wendell L. French and Cecil H. Bell, Organization Development: Behavioral Science Interventions for Organization Improvement, 6th ed. (Upper Saddle River, N.J.: Prentice Hall, 1999), 26.

19. David G. Carnevale, Organizational Development in the Public Sector (Boulder, Colo.: Westview Press, 2003).

20. Holloway, "The Significance of Organizational Development in Academic Research Libraries"; Stephens and Russell, "Organizational Development, Leadership, Change, and the Future of Libraries."

21. Janet H. Parsch and M. Sue Baughman, "Towards Healthy Organizations: The Use of Organization Development in Academic Libraries," Journal of Academic Librarianship 36, no. 1 (Jan. 2010): 3-19, doi:10.1016/j.acalib.2009.11.002.

22. Megan Oakleaf, "Are They Learning? Are We? Learning Outcomes and the Academic Library," Library Quarterly 81, no. 1 (Jan. 2011): 61-82, doi:10.1086/657444.

23. David A Garvin, "Building a Learning Organization," Harvard Business Review 71, no. 4 (1993): 78.

24. Peter M. Senge, The Fifth Discipline: The Art and Practice of the Learning Organization, rev. ed. (New York: Doubleday/Currency, 2006).

25. Joan Giesecke and Beth McNeil, "Transitioning to the Learning Organization," Library Trends 53, no. 1 (2004): 58.

26. Giesecke and McNeil, "Transitioning to the Learning Organization."

27. Giesecke and McNeil, "Transitioning to the Learning Organization"; Rena K. Fowler, "The University Library As Learning Organization for Innovation: An Exploratory Study," College E Research Libraries 59, no. 3 (1998): 220-31.

28. Giesecke and McNeil, "Transitioning to the Learning Organization."

29. Fowler, "The University Library As Learning Organization for Innovation: An Exploratory Study."

30. Giesecke and McNeil, "Transitioning to the Learning Organization"; Jan Hayes, Maureen Sullivan, and Ian Baaske, "Choosing the Road Less Traveled: The North Suburban Library System Creates a Learning Organization," Public Libraries 38, no. 2 (1999): 110-14; Laura J. Bender, "Team Organization-Learning Organization: The University of Arizona Four Years into It," Information Outlook 1, no. 9 (1997): 19-22; Christy Hightower and George Soete, "The Consortium as Learning Organization: Twelve Steps to Success in Collaborative Collections Projects," Journal of Academic Librarianship 21, no. 2 (1995): 87-91.

31. Giesecke and McNeil, "Transitioning to the Learning Organization."

32. Holloway, "The Significance of Organizational Development in Academic Research Libraries."

33. Wood, Miller, and Knapp, Beyond Survival: Managing Academic Libraries in Transition, 41.

34. Association of College and Research Libraries, Value of Academic Libraries: A Comprehensive Research Review and Report.

35. McNicol, "The Challenges of Strategic Planning in Academic Libraries."

36. Giesecke and McNeil, "Transitioning to the Learning Organization."

37. Richard M. Dougherty, "Planning for New Library Futures," Library Journal 127, no. 9 (2002): 38-41; Higher Education Funding Council for England, Strategic Planning in Higher Education: A Guide for Heads of Institutions, Senior Managers and Members of Governing Bodies (Bristol, UK, 2000); Valerie Jackson Feinman, "Five Steps toward Planning Today for Tomorrow's Needs," Computers in Libraries 19, no. 1 (1999): 18-21.

38. Senge, The Fifth Discipline: The Art and Practice of the Learning Organization; Giesecke and McNeil, "Transitioning to the Learning Organization."

39. Holloway, "The Significance of Organizational Development in Academic Research Libraries"; Amos Lakos and Shelley E. Phipps, "Creating a Culture of Assessment: A Catalyst for Organizational Change," portal: Libraries and the Academy 4, no. 3 (2004): 345-361, doi:10.1353/ pla.2004.0052.

40. Lakos and Phipps, "Creating a Culture of Assessment: A Catalyst for Organizational Change."

41. Robert E Dugan and Peter Hernon, "Outcomes Assessment: Not Synonymous with Inputs and Outputs," Journal of Academic Librarianship 28, no. 6 (Nov. 2002): 376-80, doi:10.1016/S00991333(02)00339-7.

42. Lakos and Phipps, "Creating a Culture of Assessment: A Catalyst for Organizational Change," 347.

43. Giesecke and McNeil, "Transitioning to the Learning Organization."

44. Ibid.

45. Janet H. Parsch and M. Sue Baughman, “Towards Healthy Organizations: The Use of 
Organization Development in Academic Libraries," Journal of Academic Librarianship 36, no. 1 (2010): 3-19, doi:10.1016/j.acalib.2009.11.002; McNicol, "The Challenges of Strategic Planning in Academic Libraries"; Holloway, "The Significance of Organizational Development in Academic Research Libraries."

46. Lisa Given, "Qualitative Research in Evidence-Based Practice: A Valuable Partnership," Library Hi Tech 24, no. 3 (2006): 378, doi:10.1108/07378830610692145.

47. T.S. Palys and Chris Atchison, Research Decisions: Quantitative and Qualitative Perspectives, 4th ed. (Toronto: Thomson Nelson, 2008), 22.

48. Given, "Qualitative Research in Evidence-Based Practice: A Valuable Partnership."

49. Klaus Krippendorff, Content Analysis: An Introduction to Its Methodology, 3rd ed. (Los Angeles: SAGE, 2013), 24.

50. Colin Robson, Real World Research: A Resource for Users of Social Research Methods in Applied Settings, 3rd ed. (Chichester, U.K.: Wiley, 2011); Ann Marshall, Vicki Burns, and Judi Briden, "Know Your Students: Rochester's Two-Year Ethnographic Study Reveals What Students Do on Campus and How the Library Fits In," Library Journal 132, no. 18 (2007): 26-29.

51. Marilyn Domas White and Emily E. Marsh, "Content Analysis: A Flexible Methodology," Library Trends 55, no. 1 (2006): 22-45, doi:10.1353/lib.2006.0053.

52. Krippendorff, Content Analysis: An Introduction to Its Methodology; John W. Creswell, Qualitative Inquiry \& Research Design: Choosing among Five Approaches, 2nd ed. (Thousand Oaks, Calif.: SAGE Publications, 2007); White and Marsh, "Content Analysis: A Flexible Methodology."

53. David W. Pickton and Sheila Wright, "What's Swot in Strategic Analysis?" Strategic Change 7, no. 2 (Mar. 1998): 101-09, doi:10.1002/(SICI)1099-1697(199803/04)7:2<101::AID-JSC332>3.0.CO;2-6.

54. Kevin Brennan, A Guide to the Business Analysis Body of Knowledge (BABOK Guide), version 2 (Toronto: International Institute of Business Analysis, 2009), 217-18. 